\title{
Use of IT platform in determination of efficiency of mining machines
}

\author{
Jarosław Brodny ${ }^{1, *}$ and Magdalena Tutak $^{2}$ \\ ${ }^{1}$ Silesian University of Technology, 26-28 Roosevelta St., 41-800 Zabrze, Poland \\ ${ }^{2}$ Silesian University of Technology, 2 Akademicka St., 44-100 Gliwice, Poland
}

\begin{abstract}
Determination of effective use of mining devices has very significant meaning for mining enterprises. High costs of their purchase and tenancy cause that these enterprises tend to the best use of possessed technical potential. However, specifics of mining production causes that this process not always proceeds without interferences. Practical experiences show that determination of objective measure of utilization of machine in mining enterprise is not simple. In the paper a proposition for solution of this problem is presented. For this purpose an IT platform and overall efficiency model OEE were used. This model enables to evaluate the machine in a range of its availability performance and quality of product, and constitutes a quantitative tool of TPM strategy. Adapted to the specificity of mining branch the OEE model together with acquired data from industrial automatic system enabled to determine the partial indicators and overall efficiency of tested machines. Studies were performed for a set of machines directly use in coal exploitation process. They were: longwall-shearer and armoured face conveyor, and beam stage loader. Obtained results clearly indicate that degree of use of machines by mining enterprises are unsatisfactory. Use of IT platforms will significantly facilitate the process of registration, archiving and analytical processing of the acquired data. In the paper there is presented methodology of determination of partial indices and total OEE together with a practical example of its application for investigated machines set. Also IT platform was characterized for its construction, function and application.
\end{abstract}

\section{Introduction}

The dynamic development of Information and Communication Technologies (ICTs) has resulted in their increasing application in various areas of social and economic life. Nowadays, an increasing number of companies deploy cutting-edge IT tools to streamline their management processes. The practical application of these solutions improves the effectiveness of such companies, thus enhancing their competitiveness. The universal accessibility of advanced IT solutions and the growing competitiveness encourage other sectors to apply similar solutions. This is also true of the extractive industry and hard coal mining in particular. The growing competition on the energy market and the positive effects

\footnotetext{
Corresponding author: jaroslaw.brodny@polsl.pl
} 
of implementing IT tools into corporate management processes in other sectors have necessitated changes in mining companies as well. These companies are showing increasing interest in the application of IT tools to enhance their operational efficiency.

The area for which such tools are especially suitable is maintenance management. The use of state-of-the-art technologies, increasing automation of production processes and growing requirements as to the economic results are placing ever higher demands on maintenance departments $[1,2]$. To address these demands, maintenance departments are forced to make wider use of the IT solutions offered. One of the primary goals set for these departments is to take full advantage of the technical resources owned by a given company. In the extractive industry, this mainly concerns the effective use of all types of machinery possessed by companies.

Determining the effectiveness of utilising mining machines is of the utmost importance for mining companies. The high costs of purchasing and leasing these machines make the companies strive to take as full advantage of their technical potential as possible. However, due to the specificity of mining production, this process does not always continue without disruptions. Practical experiences show that it is not easy to determine an objective measure for the utilisation of mining machines.

The relevant actions taken thus far in Poland have not had a significant impact. The effectiveness of utilising machines, especially those directly involved in mining the rock mass, is very low [3,4]. At the same time, the methods applied to determine this effectiveness, based on dispatchers' subjective notes, do not guarantee objectivity of the resulting assessments.

The issue of assessing the effectiveness of machinery use in the extractive industry worldwide is addressed by few researchers. In their works, they use the OEE model $[5,6]$ and indicator based methods [7], as well as the reliability theory [7]. These works, however, are primarily focused on open-pit mines [5-7], whose specificity differs significantly from that of underground mines. The differences are particularly related to the conditions of the exploitation operations, including ventilation, existing hazards (methane, fire) and the deformative impact of the rock mass. The subject of machinery operation in underground mines has been discussed in publication [8], which presents the results of the effectiveness assessment for the operation of the longwall shearer in the Parvadeh coal mine, Iran. The analysis of these results unambiguously indicates that the operating conditions of underground mining machinery are very complicated. At the same time, such conditions make it difficult to achieve high effectiveness indicators. However, most of the data used for the analysis were acquired from reports by representatives of the mining supervision, which does not guarantee full objectivity of the data.

For this reason, the authors of this paper based their analyses on the data acquired from industrial automation systems, since they guarantee complete objectivity and reliability. At the same time, they provide great possibilities for analysing and interpreting the results obtained. It is indeed evident that the effectiveness of the machinery currently used in the hard coal mining industry in Poland is unsatisfactory.

The paper presents a proposal for how to solve this problem. To this end, use was made of an IT platform and the Overall Equipment Effectiveness (OEE) model [9, 10]. This model not only allows for assessing a given machine's operation in the areas of its availability, performance and quality of the product, but it also constitutes a quantitative tool of the TPM strategy [9-12]. Adapted to the specificities of the extractive industry, the OEE model - in combination with the data acquired from the industrial automation system - made it possible to determine the subindicators and the overall efficiency indicator of the machines under examination. The research was conducted for a machine combination directly involved in the process of coal exploitation, including a longwall shearer along 
with an armoured face conveyor and a beam stage loader. These machines are part of an automated longwall system.

The IT platform was used to determine the effectiveness of these machines. In the case at hand, the platform is understood to mean a set of interrelated components of IT techniques and technologies from the field of hardware, ICT and software infrastructure. This tool allows for practical application of the OEE methodology in the underground mining environment. The platform is primarily based on relational databases along with algorithms for data analysis. Accessible to the particular groups involved in the production and management processes, the platform makes it possible to generate results, as appropriate, and access the data. Generally, it may be presumed that the platform offers easy access to the information on the work of machinery for different decision-making levels in the mining company and the group of companies which includes the mine in question. At the same time, its structure is so universal that it can be used for a number of longwalls and mines.

The paper discusses the general structure of the IT platform and presents the results of its application for one of the longwalls in a hard coal mine. In the case at hand, the possibilities of the IT platform were used only partially. This is due to the fact that attention was focused on determining the effectiveness of utilising the machines directly involved in coal exploitation. However, it is expected to encompass a broader group of machines and users. In the authors' opinion, the platform developed should constitute an essential tool for supporting the management system of production processes, with the use of the OEE methodology.

\section{Description of the IT platform}

The dynamic changes in the area of maintenance, increased reliability of production equipment and machinery performance may be addressed by developing new methods and techniques that support the operations of maintenance departments. These changes also affect the mining industry. The globalisation leading to widespread competitiveness may be addressed by using increasingly sophisticated solutions that support corporate management processes. The Polish coal mining industry has a well ordered internal structure, which also encompasses the management of technical resources and company maintenance. However, in practice, it appears that the resources possessed are not capable of fully optimising the production process. Therefore, the new challenges faced by the mining industry necessitate the use of cutting-edge information and communication technologies (ICTs) in the management of mining companies.

In practice, such companies have already implemented certain IT tools with a view to supporting the management of resources and safety as well as further training of employees. However, the area of machinery operation lacks an efficient and reliable tool for objective (independent from the employee's subjective feelings) determination of the utilisation effectiveness of this machinery.

Such possibilities are offered by the IT platform which provides quick, flexible and unlimited access to data resources and information on the operation of the machinery under examination. This information is obtained for the purpose of managing the operational process and supporting business, educational and research processes. It can be assumed that platform, which has been designed and is currently being deployed, is a tool that allows for using IT technologies to support knowledge management in a production company, thereby facilitating effective flow of information coming from various sources amongst recipients for efficient and knowledge-based management of the production process [13-18].

The platform in question is therefore a solution which constitutes an integrated set of tools, including: 
- $\quad$ administering, data-feeds and archiving measurement data (DW - Data Warehouse);

- administering the processing of measurement data to the form and scope relevant for determining a tree of the OEE indicators;

- securing the information layer on the production process on the longwalls for which the methodology adopted will be used;

- administering the calculation of OEE indicators;

- securing the information layer for analyses related to the methodology applied;

- administering the presentation and reporting layers.

The main component of the tool is the Data Warehouse (DW) composed of a series of relational databases. They contain input data on the operational parameters of the machinery examined, computation algorithms and result-based databases. Particular importance must be given to input data. It is their quality and the accuracy of the analytical process that determine the quality of the results obtained. In order to reduce the problems related to data acquisition and ensure systemic processing mechanisms, further layers of data were introduced for subsequent transformations:

- $\quad$ the layer of source (raw) data (offline data, file databases, online data);

- $\quad$ the layer of standardised source data (DW, layer I);

- $\quad$ the layer of selected, standardised source data (DW, layer II);

- the layer of processed data based on the model of time buckets necessary to determine the OEE indicator (DW, layer III).

The OpenEye system was used for the management of the entire IT mechanism and the data acquired in particular. This solution uses elements of the supervisory control and data acquisition (SCADA) system. It is made up of a series of tools for quick data analysis and visualisation of the results obtained. The OpenEye system contains built-in visualisation products and cooperates with any relational databases, including Oracle, MS SQL and PostgreSQL.

The structure of the platform allows for direct cooperation with the SZYK2 management support system commonly used in Polish mines. Referential integrity with the KPT module (Production-Technical Complex) of this system was implemented. This module is responsible for supporting the administration of business processes related to production as well as its preparation and maintenance. This allows for direct acquisition of the data on the parameters of the machines in operation, the mining and geological conditions, the geometry of mine workings as well as much more information and the mining operations in progress.

The whole system also includes a series of components from an industrial automation system (sensors, controllers, relays, etc.), an optical fibre transmission network and an entire data archiving and processing system. The main parts of the entire system include engines for data acquisition, archiving and analytical processing, for reporting and visualisation, as well as an engine for exchanging information, opinions and inserting comments.

Figure 1 presents the diagram of the acquisition process for the data on machinery operating parameters. It is one of the fundamental parts of the entire IT system, demonstrating the manner of creating databases for the particular layers of data. A particularly important role in this process is played by the removal of holes in the data acquired and the qualification of the data for further processing. As a result of this action, data are supplied to the part of the data warehouse which contains the database of processed data. These data give rise to further analytical processing.

Additionally, the system has been equipped with an engine for registering the causes of downtimes for the particular machines. The module of the IT platform for registering unscheduled downtimes of machines may be viewed in Figure 2 (original view with description in the Polish language). 


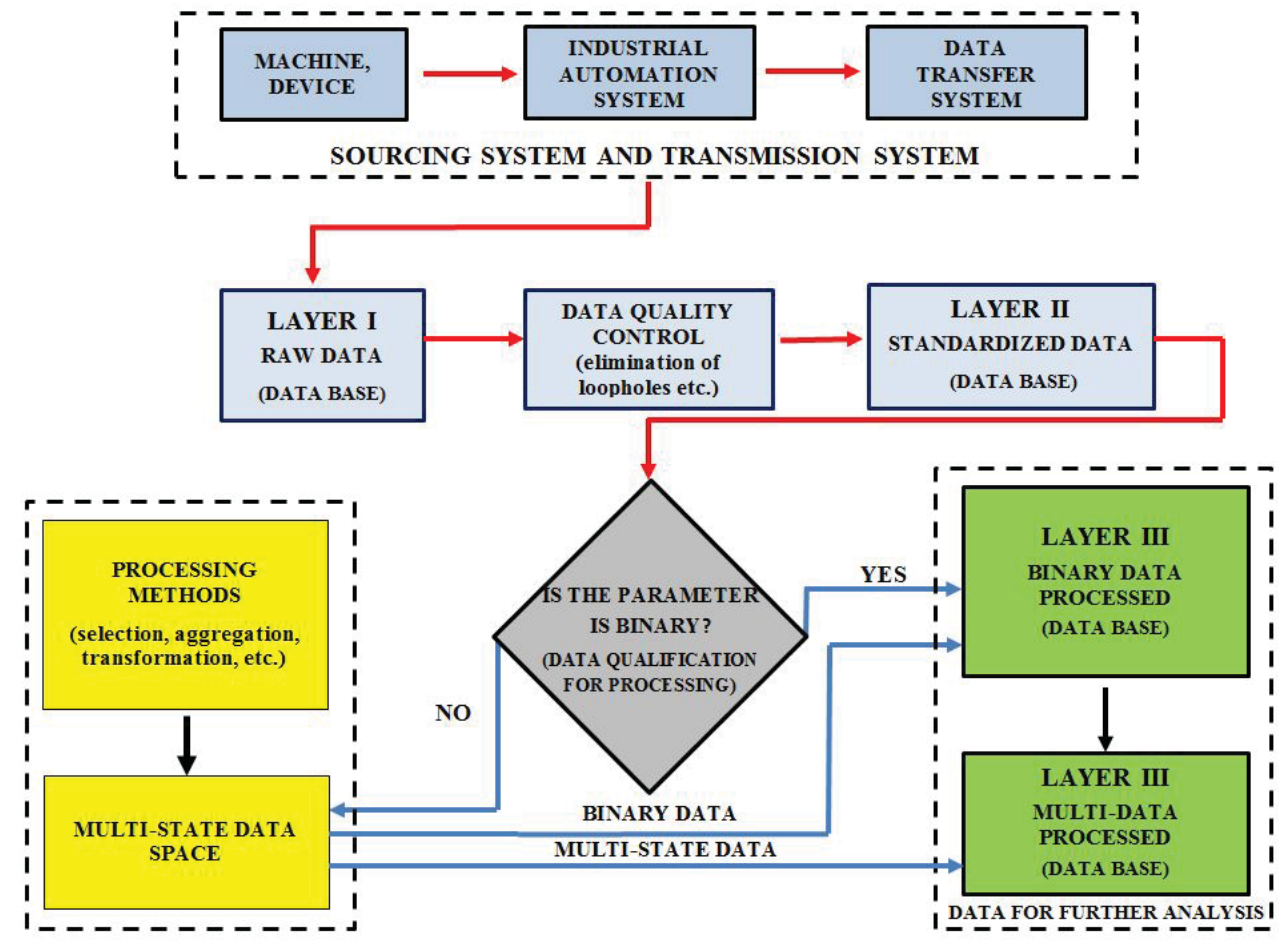

Fig. 1. The diagram of the acquisition process for the data on machinery operating parameters.

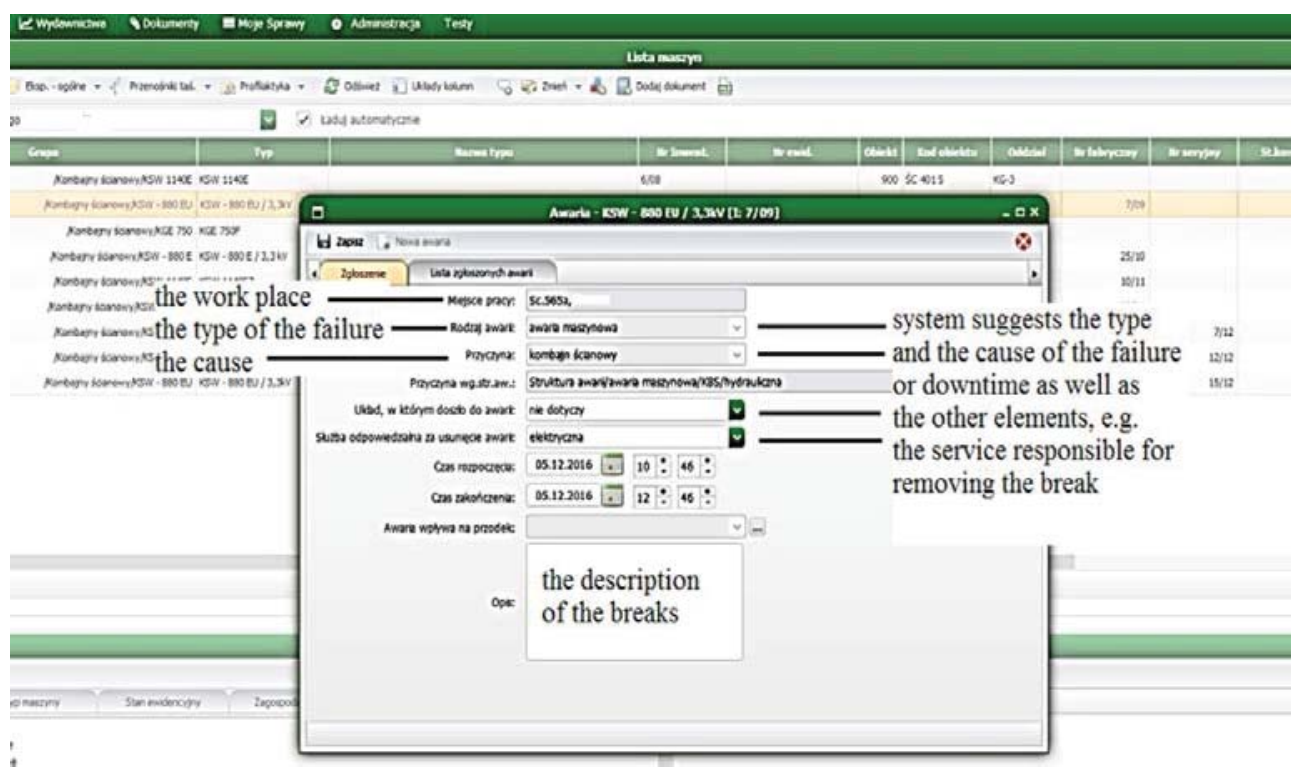

Fig. 2. The module of the IT platform for registering unscheduled downtimes of machines.

It should also be highlighted that one of the important objectives behind the implementation of the solution presented is the possibility of exchanging views and comments for all the individuals involved in mining exploitation. This applies to employees and dispatchers as well as the management of the group of companies. 


\section{Description of the IT platform}

The solution in question was used to assess the operational effectiveness of the machines integrated into an automated longwall system for three longwalls in one of the hard coal mines. The publication demonstrates its practical application for one of these longwalls. The results presented encompass merely a small part of what was obtained from this longwall.

The longwall examined was 139 metres long and approximately 3.0 metres high, with the longwall panel length amounting to approximately 750 metres. The longwall's longitudinal inclination was 10 , while its transverse inclination - 6o. The longwall was located in seam 510 at the depth of 665 metres. The only major risk in the area of the longwall was the methane hazard, which had no greater influence on the exploitation process. It can therefore be assumed that the exploitation conditions were acceptable.

In the case of the mine under examination, exploitation is carried out in a unidirectional mining system. The longwall shearer's operating cycle consists of the sumping phase, coalgetting and reverse (manoeuvring) motion. The average advance speed of the shearer during coal-getting operations is approx. 5-6 m/min., and within the range of 16-20 $\mathrm{m} / \mathrm{min}$. during a reverse motion.

The effectiveness of the machinery set under examination was determined by means of the Overall Equipment Effectiveness (OEE) model. Due to the specificity of the mining industry and the underground exploitation of hard coal in particular, the manner of calculating the particular indicators of the OEE method was modified. These modifications covered all three indicators $[3,4]$. The availability $(A)$ for each of the machines examined was determined as the ratio of the actual working time $\left(T_{r}\right)$ of a given machine to the productive time $\left(T_{w}\right)$ of its work. The latter is also referred to as the operational time and constitutes part of the normative time $\left(T_{n}\right)$ less scheduled downtimes $\left(T_{p}\right)$. On the other hand, the actual working time of a machine is calculated as the difference between the productive (operational) time and the duration of unscheduled downtimes $\left(T_{u}\right)$. The dependency which makes it possible to determine the availability indicator has been presented in the following equation (1):

$$
A=\frac{T_{r}}{T_{w}}=\frac{T_{w}-T_{u}}{T_{n}-T_{p}}
$$

The most crucial component of the availability indicator is the actual working time of a machine. The methodology at hand used discreet methods to register the operational parameters of the machines examined. In the case of the longwall shearer, these included the amperage values of the currents consumed by the shearer's motors, the speed of advance and the shearer's location in the longwall specified in relation to the powered support section. In the case of the armoured face conveyor, the registration encompassed the amperage values of the currents consumed by the motors of its drives, while in the case of the beam stage loader - the amperage of the current consumed by its propulsion engine.

The actual working times of these machines $\left(T_{r}\right)$ were calculated based on the registered behaviours. It was assumed that the difference between the actual time $\left(T_{r}\right)$ and the productive (operational) time $\left(T_{w}\right)$ constituted unscheduled downtimes for a given machine. The algorithms used made it possible to determine these times and the duration of the particular downtimes.

The productivity indicator $(E)$ was defined as the ratio of the actual quantity of the mined rock mass in tonnes $\left(E_{r}\right)$ to the quantity of the mined rock mass in tonnes as assumed in the technical plan $\left(E_{n}\right)$. This indicator thus specifies the ratio of actual productivity to that assumed in the technical plan for the given longwall. 


$$
E=\frac{E_{r}}{E_{n}}
$$

The productivity indicator was determined based on the registration of the actual productivity of each working shift, conducted by dispatchers. Additionally, accurate measurements were taken of the exploited area every ten days. On that basis, with account being taken of the assumed densities of the mined rock, the actual mass of the mined rock was determined. No significant deviations were noted in this regard during the examinations.

The most difficult to actually determine in underground conditions is the excavated coal quality indicator. The mines in question have no systems for continuous control of the excavated coal material quality. Once this indicator had been determined, use was made of the information obtained from the mine's preparation plant and the excavated coal quality control department. Based on the examination results of the excavated coal quality, carried out once every ten days, and the coal size assessed during each working shift, the excavated coal quality indicator $(Q)$ was determined.

This indicator was determined as the ratio of the actual excavated coal quality $\left(Q_{r}\right)$ to that assumed in the technical plan for the given longwall $\left(Q_{p}\right)$, with both of these factors taking into account the quantity of the gangue in the excavated coal material and the coal size (3).

$$
Q=\frac{Q_{r}}{Q_{p}}
$$

The value of the total OEE indicator was calculated as the product of the particular subindicators (4):

$$
O E E=A \times E \times Q \times 100 \%
$$

The dependencies presented were used to determine the values of the subindicators as well as the total OEE indicator for the particular machines and the entire machine combination for a single working shift (Fig. 3).

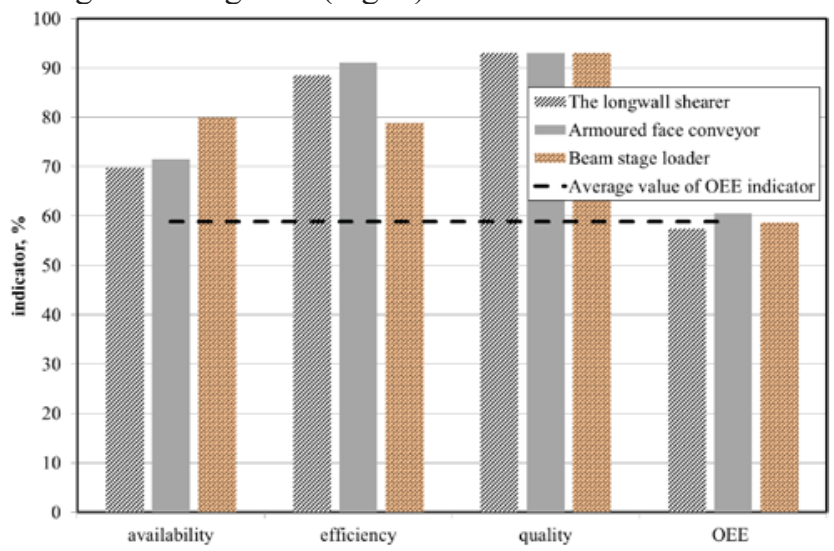

Fig. 3. The values of the subindicators as well as the total OEE indicator for the particular machines and the entire machine combination for a single working shift.

Figure 4 presents the values of the overall equipment effectiveness (OEE) indicators for the particular machines under examination and the average value for the entire machine combination for 30 working shifts (for one measurement decade). Figure 5 presents average 
values of unscheduled downtimes per one working shift for the particular machines. After determining these times, it was assumed that a working shift lasted 6 hours, or 360 minutes.

Based on the data registered, it is also possible to analyse the unscheduled downtimes of the machines examined. This analysis may encompass the structure of these downtimes and their causes. The results obtained may constitute a very important source of information for users and machine producers alike.

Figure 6 presents a summary of the quantity of unscheduled downtimes for the armoured face conveyor and the beam stage loader registered by the industrial automation system. The summary also takes into account the structure of these downtimes. Their duration was divided into six sections. The summary covers the entire period under examination, i.e. 30 working shifts.

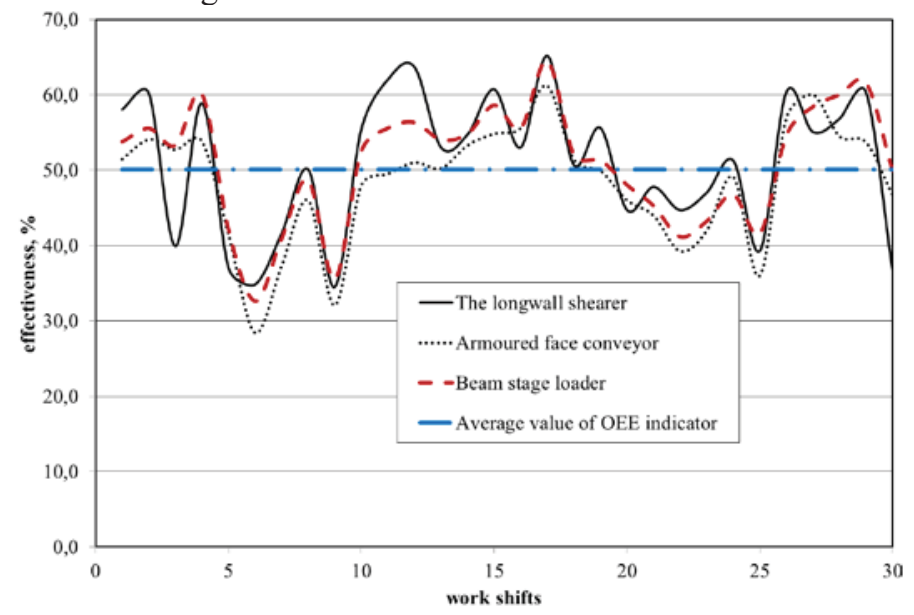

Fig. 4. The values of the overall equipment effectiveness (OEE) indicators for the particular machines under examination and the average value for the entire machine combination for 30 working shifts (for one measurement decade).

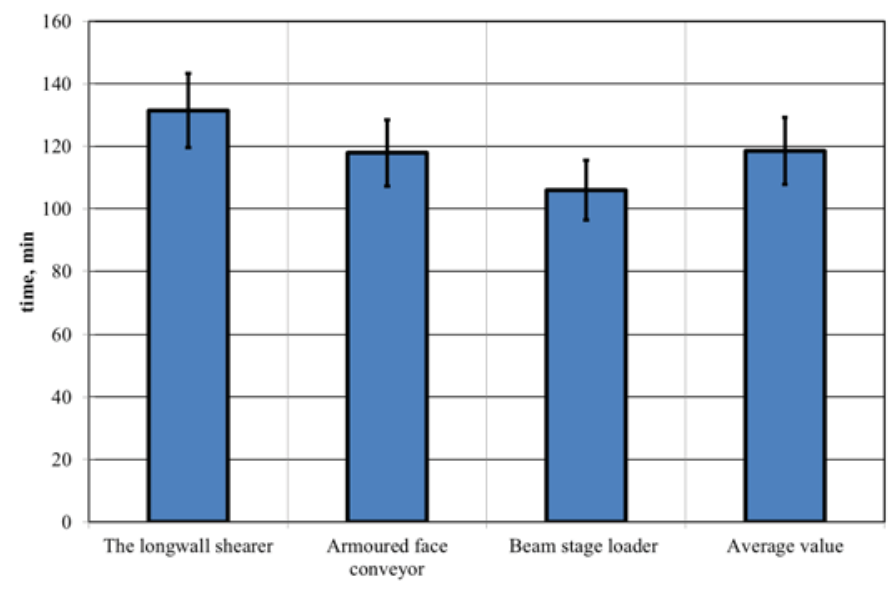

Fig. 5. The average values of unscheduled downtimes per one working shift for the particular machines. 


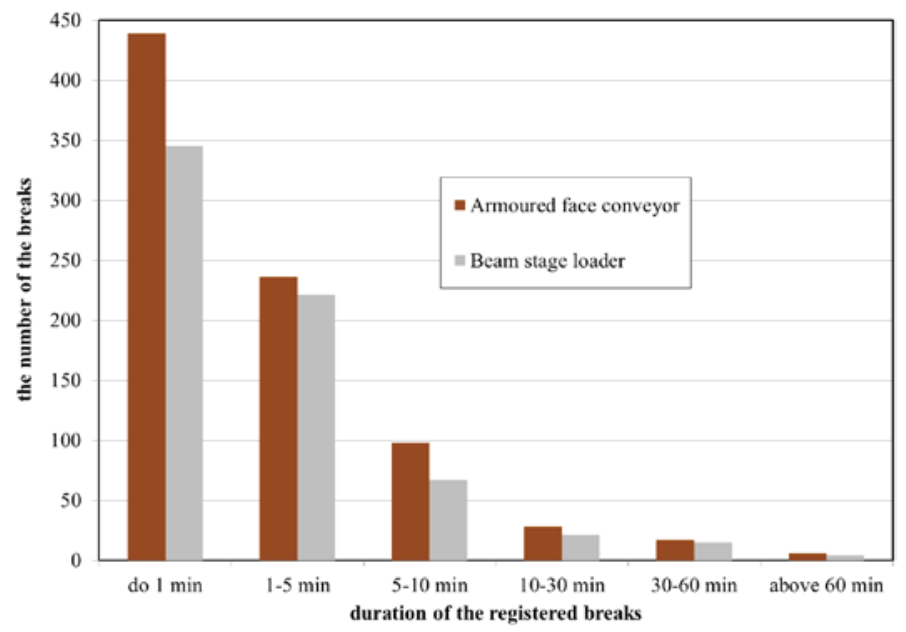

Fig. 5. The quantity of unscheduled downtimes for the armoured face conveyor and the beam stage loader registered by the industrial automation system.

\section{Conclusions}

The IT platform presented and discussed in the publication is intended to support the maintenance management process in a mining company. It is one of the main areas offering considerable reserves for optimising the hard coal production process in Polish mines. In the authors' opinion, the IT solution in question may significantly facilitate this process.

The paper presents only some of the analytical and cognitive possibilities offered by the platform. First and foremost, it allows for direct information exchange (both online and offline) between all the individuals and institutions involved in the production process that uses the machines under examination.

Another significant aspect is the fact that, in the area of identifying the causes of unscheduled downtimes, the personnel in charge of inputting this information remain anonymous. This makes it possible to acquire tacit knowledge, which, so far, has been practically impossible to acquire due to employees' solidarity. Using the industrial automation system to acquire data on the operational parameters of the machines allowed for complete verification of the information registered by the dispatchers. Ever since the system was implemented, there has been a significant improvement in the quantity and quality of the information provided by the dispatchers.

Currently, the system is used for analysing the operation of the machines in the automated systems of two longwalls. Thanks to full integration with the management support system, the measurement data, along with additional information, are transferred to the platform in the online system. The system provides quick access to information, both within the mine (for the particular decision-making levels) and for external units (the management of the group of companies, the manufacturers of the machines, scientific bodies, etc.). It may therefore be assumed that the IT platform allows for collecting and processing information on the work of the machines (their operation), and exchanging such information between all individuals having access to this process.

The methodology presented in the paper for acquiring and analysing data on machine operation as well as the results obtained indicate that the actions taken offer extensive possibilities for examining and assessing the operation of these machines. It should subsequently allow for improving the effectiveness of their use and produce positive effects on the company's economic performance. It should be noted that the improvement is also 
dependent on certain external factors, which may be of paramount importance in the case of underground exploitation.

The detailed analysis of the results obtained in terms of the effectiveness of using the machines under examination demonstrates a great potential for improving the indicators determined. The obtained values of these indicators are unsatisfactory. Within the data presented in the paper (30 working shifts) and the entire longwall under exploitation

( 8 months), none of the working shifts exceeded the effectiveness value of $66 \%$. During the period covered in the paper, the highest value of the effectiveness indicator recorded was $65.19 \%$. The average value of this indicator for that period amounted to $50,14 \pm 7,64 \%$.

Despite the specificity of mining exploitation already mentioned, the results obtained are unsatisfactory. In the subsequent stages of work on this issue, it seems advisable to undertake a deeper analysis of the causes behind such a low utilisation of the machines of the longwall system. After all, it appears that the mining industry offers considerable reserves in the area of utilising the technical resources possessed.

To conclude, it may be stated that the application of the OEE model, in combination with state-of-the-art IT solutions, makes it possible to objectively monitor and assess the operating status of mining machinery. The information acquired may give rise to actions undertaken with a view to improving these indicators and optimising the process of coal exploitation. Due to editorial requirements (i.e. limited page-count of a publication), the paper discusses only selected parts of the system's operation. However, the authors anticipate further publications in this area.

This article is the result of the research project No. PBS3/B6/25/2015 „Aplication of the Overall Equipment Effectiveness method to improve the effectiveness of the mechanized longwall systems work in the coal exploitation process" realized in 2015-2017, financed by NCBiR.

\section{References}

1. P.C. Cozzucoli, J. Qual. Stati. Rel., Vol. 2009, (2009)

2. K. Kandananond, Qual. Stati. Rel., Vol. 2010, (2010)

3. J. Brodny, M. Tutak, M. Michalak, Beyond Databases, Architectures and Structures. Towards Efficient Solutions for Data Analysis and Knowledge Representation. DOI: 10.1007/978-3-319-58274-0_35 (2017)

4. K. Stecuła, J. Brodny, M. Tutak, GeoConference SGEM, Conference Proceedings, Book1 Vol. 2, 65-72, DOI: 10.5593/SGEM2016/B12/S03.009 (2016)

5. M. Mohammadi, P. Rai, S. Gupta, Arch. Min. Sci. 62, 1, 105-120, DOI 10.1515/amsc2017-0008 (2017)

6. S. Elevli, B. Elevli, Acta Mont. Slov. Vol. 15, číslo 2, 95-101 (2010)

7. M. Mohammadi, P. Rai, S. Gupta, Acta Mont. Slov. Vol. 21, no 1, 1-8 (2016)

8. S.H. Hoseinie, B. Ghodrati, U. Kumar, Sixth International Symposium High Performance Mining, (2014)

9. W. Mazurek, Wskaźnik OEE - Teoria i praktyka, wydanie II Neuron (2014)

10. S. Nakajima, Introduction to TPM, Productivity Press (1988)

11. B. Gajdzik, Log., $\mathrm{nr} 3$ (2014)

12. Japan Institute of Plant Maintenance: TPM dla każdego operatora. The Productivity Press Development Team (2012)

13. R.M. Grant, Strat. Manag. J., Nr 17, 109-122 (1996)

14. T. Gwiazda, Wstęp do informatyki w zarzadzaniu, Wyd. Wydz. Zarz. UW (2004) 
15. Z.J. Klonowski, Systemy informatyczne zarządzania przedsiębiorstwem, Oficyna Wydawnicza Politechniki Wrocławskiej (2004)

16. M. Miłosz, Eksploatacja systemów informatycznych - od teorii do praktyki (2004)

17. P. Rave, Int. J. of R. Devel, Vol. 42, no 6, (2008)

18. R.M. Stair, G. W. Reynolds, Principles of information systems, Cengage Learning (2009) 